\title{
Farfield Modeling of the Boynton Inlet Plume
}

\author{
Frederick Bloetscher \\ Florida Atlantic University, Civil Engineering Department \\ 777 Glades Road, Boca Raton, FL 33431 \\ Tel: 1-239-250-2423Ｅ-mail: h2o_man@bellsouth.net \\ Joaquin Pire-Schmidt \\ Florida Atlantic University, Civil Engineering Department \\ 777 Glades Road, Boca Raton, FL 33431 \\ E-mail: jpires@gmail.com
}

Daniel E. Meeroff

Florida Atlantic University, Civil Engineering Department

777 Glades Road, Boca Raton, FL 33431

Tel: 1-561-297-3099Ｅ-mail: dmeeroff@fau.edu

Thomas P. Carsey

National Oceanographic and Atmospheric Administration

Atlantic Oceanographic and Meteorological Laboratory, Ocean Chemistry Division

4301 Rickenbacker Causeway, Miami, FL 33149

E-mail: Thomas.P.Carsey@noaa.gov

Jack Stamates

National Oceanographic and Atmospheric Administration

Atlantic Oceanographic and Meteorological Laboratory, Ocean Chemistry Division

4301 Rickenbacker Causeway, Miami, FL 33149

E-mail: Jack.stamates@noaa.gov 
Kevin Sullivan

\begin{abstract}
National Oceanographic and Atmospheric Administration
Atlantic Oceanographic and Meteorological Laboratory, Ocean Chemistry Division
\end{abstract}

4301 Rickenbacker Causeway, Miami, FL 33149

E-mail: Kevin.sullivan\#noaa.gov

\author{
John R. Proni \\ Florida International University, Center for Engineering \& Applied Sciences \\ 10555 West Flagler St., Miami, FL 33175 \\ E-mail: jproni@fiu.edu
}

Received: July 24, 2012 Accepted: August 7, 2012

doi:10.5296/emsd.v1i2.2066ＵRL: http://dx.doi.org/10.5296/emsd.v1i2.2066

\begin{abstract}
In February, 2007, a tracer study was conducted on the Boynton Inlet, Florida, using sulfur hexafluoride $\left(\mathrm{SF}_{6}\right)$ tracer. The objectives of this study were to determine if the data collected from the tracer study could be used to develop a farfield model of the plume exiting the Boynton Inlet using limited data to develop a useful predictive result. There are few studies of the farfield movement of inlet plumes in the coastal ocean. The plume was successfully modeled with a Gaussian plume model that appears to mimic the response. It was noted that the tracer concentrated in a series of boluses that migrated north of the inlet. Because the project injected the tracer for only 4 hours during the outgoing time, a long-term result that would hide the boluses was developed. The results showed velocities lower than predicted by the measured current data. The belief is that this is partially a result of tidal influences that affect outflow from the inlet.
\end{abstract}

Keywords: inlet plume, plume model, sulfur hexafluoride

\title{
1. Introduction
}

The State of Florida is presently faced with critical decisions regarding the future of its coastal environment as a result of terrestrial activities. Nutrients and other terrestrial contaminants, accompanying a lack of long-term data on natural ocean ecosystem changes, create a difficult environment for appropriate regulatory decision-making. The impact of coastal ocean policies can have profound impacts on many areas of the economy being that they are closely linked to other decisions to be made regarding water and energy supply to the 
rapidly growing population of southeast Florida (Bloetscher, et al., 2007). Coastal ecosystems, including both inshore estuaries and offshore reefs, sustain the State of Florida's natural resource driven economy and both must be protected to continue providing economic opportunities critical to the State and to private interests. Increased nutrient loads could promote the growth of algae in areas traditionally inhabited by reefs, harming their habitat, their dependent wildlife; and affecting tourist and commercial activities (LaPointe, et al., 2005).

In southeast Florida, surface water discharges into the ocean are suspected to be one of the main sources of nutrient loads in coastal waters. However, there are no farfield studies of inlet releases in Florida. Instead the majority of studies have focused on sand movement resulting from the flux or tides and/or impact of storm events on the ocean-side debris field as opposed to farfield movement of inlet water (Creed, 2003; Hoesman, 2010; Hodgens and Krecic, 2008). The Boynton Inlet Sampling Event report (Bloetscher and Meeroff, 2007) suggested that nutrient concentrations are "highest in the inlet and downstream of it" as a result of drainage and navigation systems' discharges which mainly come from algae-laden lakes (i.e. Lake Okeechobee), detention ponds, and other hydraulic structures. These inlet waters are recharged with water from drainage and stormwater systems that contain fertilizing nutrients and urban runoff. Also, during seasonal high water table elevations, septic tanks potentially discharge nutrients and pathogens into canals and coastal waters (Meeroff et al., 2006).

\subsection{Characteristics of the Boynton Inlet}

Modeling the Boynton Inlet is extremely challenging because of the complex ambient current conditions of the system and the tidal cycles that influence its discharge rate. This inlet has a high rate of discharge (5.6 BGD, reported at the time of the release, with velocity of $5-11 \mathrm{ft} / \mathrm{s}$ depending on the point in the outgoing tidal cycle, $\mathrm{Re}>2,000,000$ ), a nearly flat ocean bottom (the slope is less than $2 \%$ ) and a barrier of reefs at about $1.5 \mathrm{~km}$ off the coast (see Figure 1). The water exiting the inlet had a total dissolved solids concentration ranging from 26,000 to $36,000 \mathrm{mg} / \mathrm{L}$ so buoyancy is unlikely a factor, unlike outfalls. Visual observation of water dynamics, along with the Reynold's number indicate that a complete mixed inlet plume moves offshore. The mouth of the inlet discharges water through a jetty structure that turns the plume E-SE. However, aerial photography of the outgoing plume obtained by NOAA shows that soon after exiting the inlet, the plume turns completely north or south, depending on the direction of the coastal current (see Figure 2). The goal of this project is to take this raw data from the Boynton Inlet and coastal ocean, and create a deterministic model of the plume's dispersion in the farfield to assess how much impact it might have on the offshore environment. This type of modeling could not be readily identified in the literature, but was noted to be distinctly different than outfalls, which have a buoyancy component not present in the inlet. 


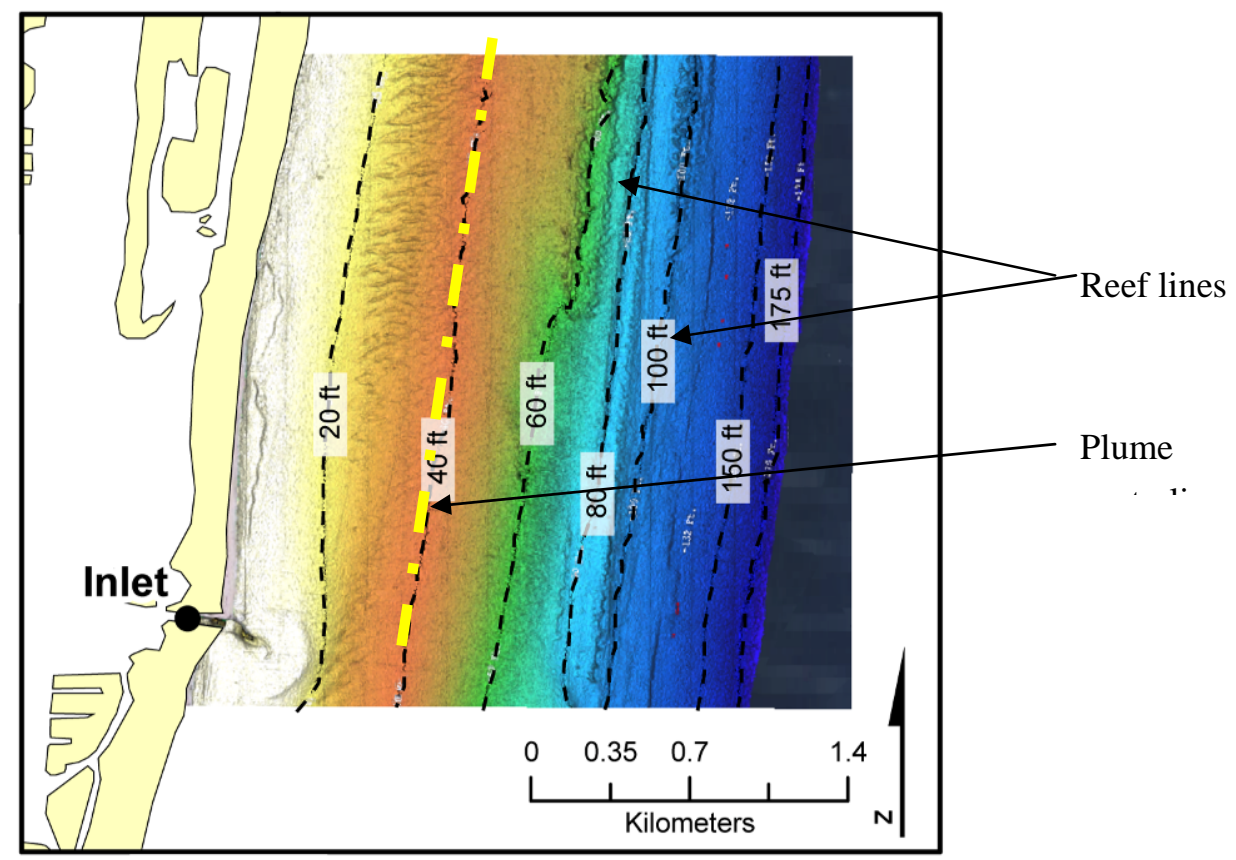

Figure 1. Bathymetric map of Boynton Inlet showing Reef lines (source: www.floridanearshore.com)

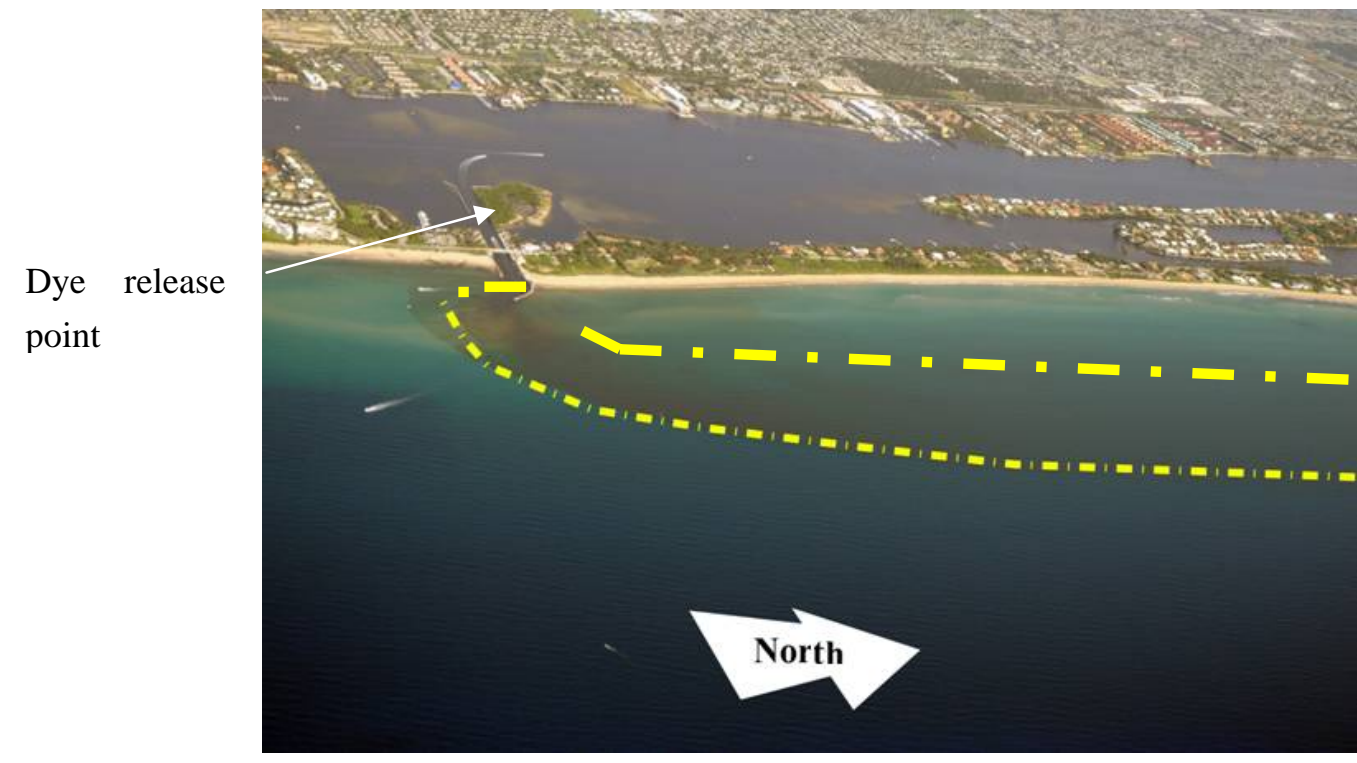

Figure 2. Plume going north. 11/07/08. Dashed line indicates apparent edge of plume. Note apparent pooling at mouth of inlet that appears to lead to a series of boluses (NOAA, 2009)

\section{Methods}

In February 2007, a sulfur hexafluoride $\left(\mathrm{SF}_{6}\right)$ tracer experiment was conducted by NOAA and Florida Atlantic University (FAU) on the Boynton Inlet, Florida. Sulfur hexafluoride had previously been used (June, 2004) to trace the coastal ocean plume of the City of Hollywood's ocean outfall (Wanninkhof, et al., 2005) to study the dilution effects on the secondary treated wastewater outfall plumes. This experiment was the first to use $\mathrm{SF}_{6}$ as an alternative to rhodamine dye as a tracer for fresh water dilution in the coastal ocean 


\section{Ml Macrothink}

(Wanninkhof, et al., 2005; Huang, 1996). Sulfur hexafluoride allows tracing the plume at higher dilutions and for longer periods of time that fluorescent dyes, with lower background concentrations and a detection limit of less than $40 \mathrm{fM}\left(1 \mathrm{fM}=10^{-15} \mathrm{~mol} \mathrm{~L}^{-1}\right)$. A krigged result of the tracer test is shown in Figure 3, with the data collection points highlighted with circles.

As the plume ages it is subject to a cascade of processes, which result in a significant diffusion and dispersion (Roberts, 1999). As shown in Figure 3, the dye appeared to move in boluses as it exited the inlet. The dynamics of this phenomenon could not be modeled and the migration of the boluses appeared to be fairly random, which may be a result of a short term release of 4 hours in the experiment. The inlet flows out every 12 hours with the tide. The tracer was released on the outgoing tide. The tracer flow was continuous for four hours, which is the time period of the initial investigation. As a result, the model assumed the use of a comparative Lagrangian framework, whereby a continuous release of the tracer was assumed, and the tracer results analyzed at discrete time periods (Ramaswami, 2005). Theoretically this works because when evaluating a series puff releases, when combining a rapid series of boluses over time, the boluses can be viewed as a continuous release and that since the model is intended to mimic continuous, long-term contributions (see Figure 4), not short-term puff (or even a small group of puffs).

Figure 5 is a conceptual diagram of the coastal area showing the inlet, nearby outfalls (located 3 miles south), the northbound Gulfstream current and the reefs. Figure 6 is a sketch showing the coordinate axes and all the variables from the surface, as well as the shoreline and the reef line (compare to Figure 1). The issue of interest here is that the depth between the surface and bottom decreases shoreward. The surface and bottom are both impenetrable boundaries and as a result they reflect the constituents.

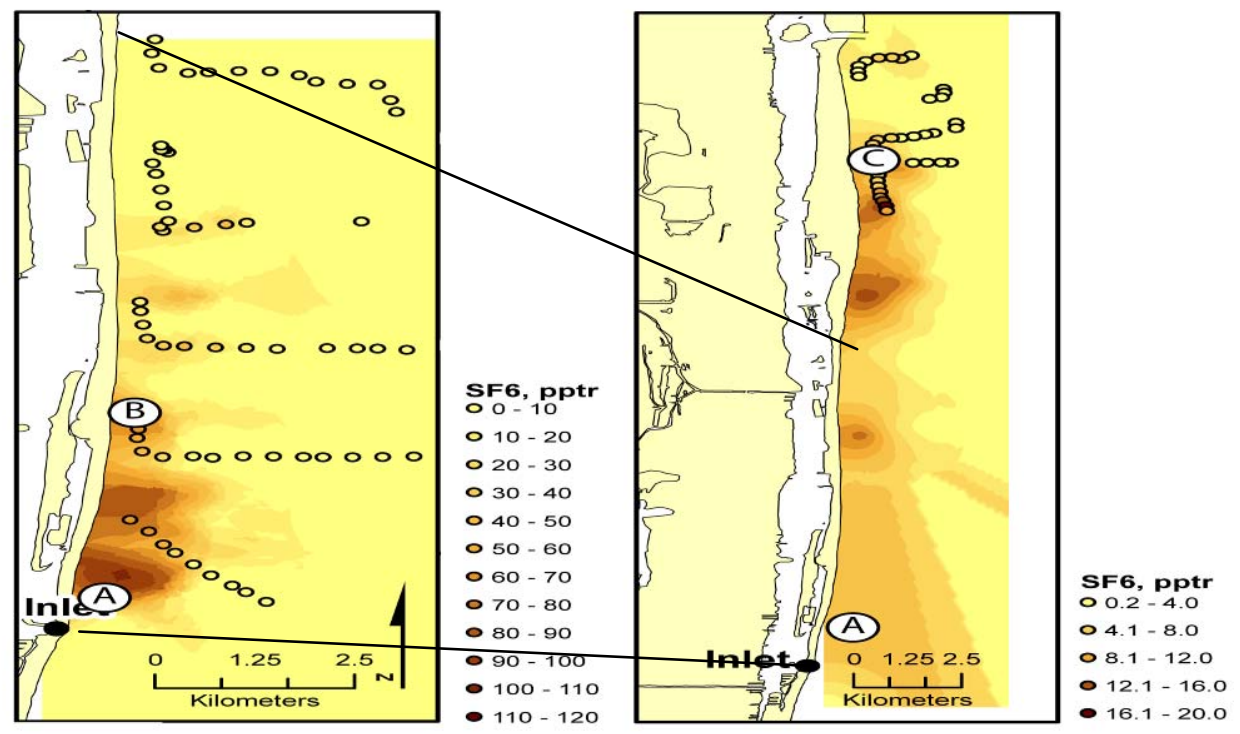

Figure 3. Krigged result of tracer test results. The small circles are data collection points. The circled letters are reference points for velocity calculation, Feb. $22^{\text {nd }}$ (left) and $24^{\text {th }}$ (right) (see later discussion) 
0<smiles>C1CCCCCCC1</smiles>

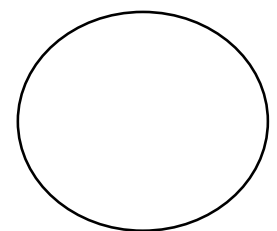

Flow Direction
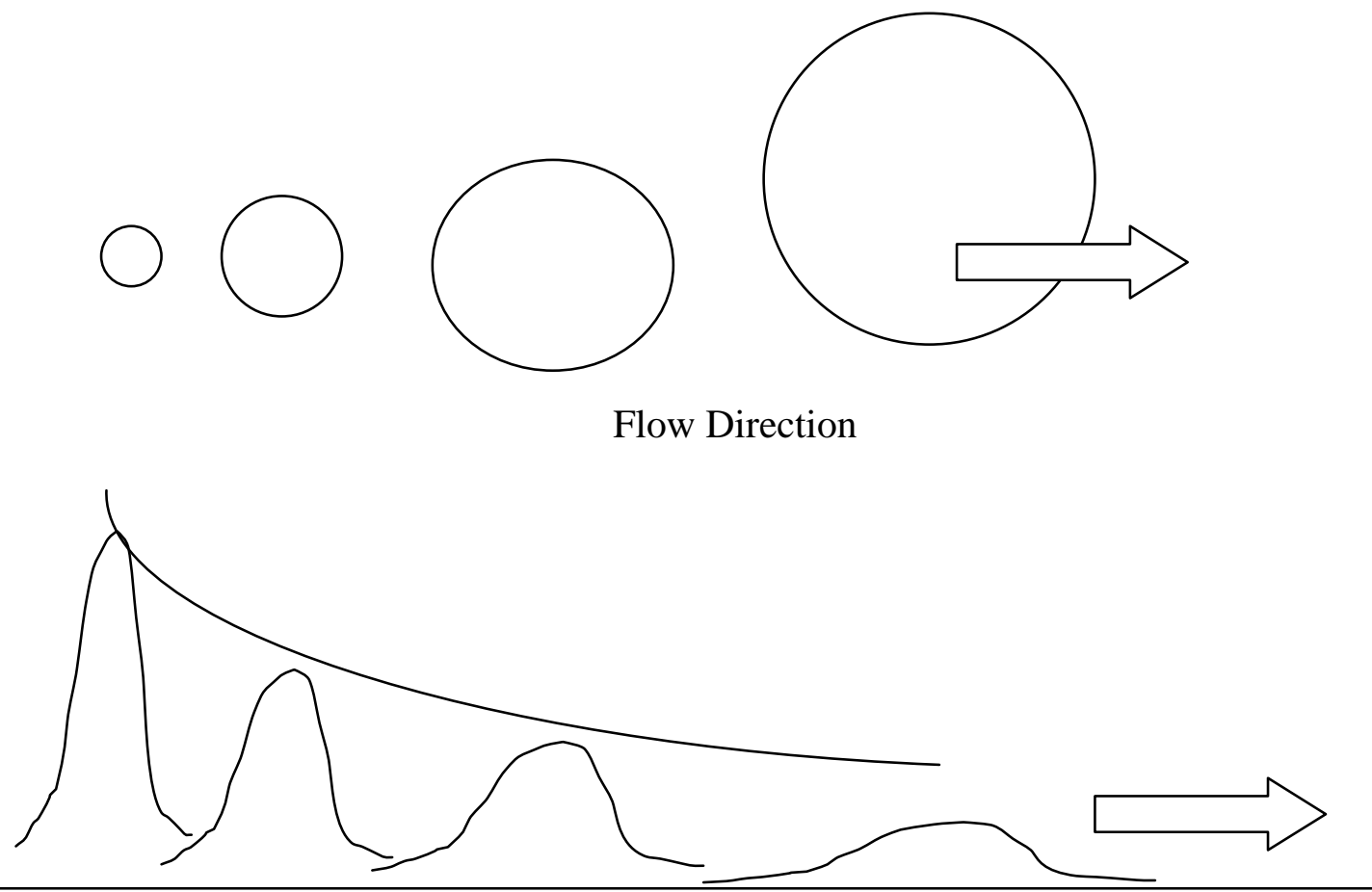

Figure 4. depiction of how a puff dilutes (spreads) with time to create an exponential distribution for the centerline

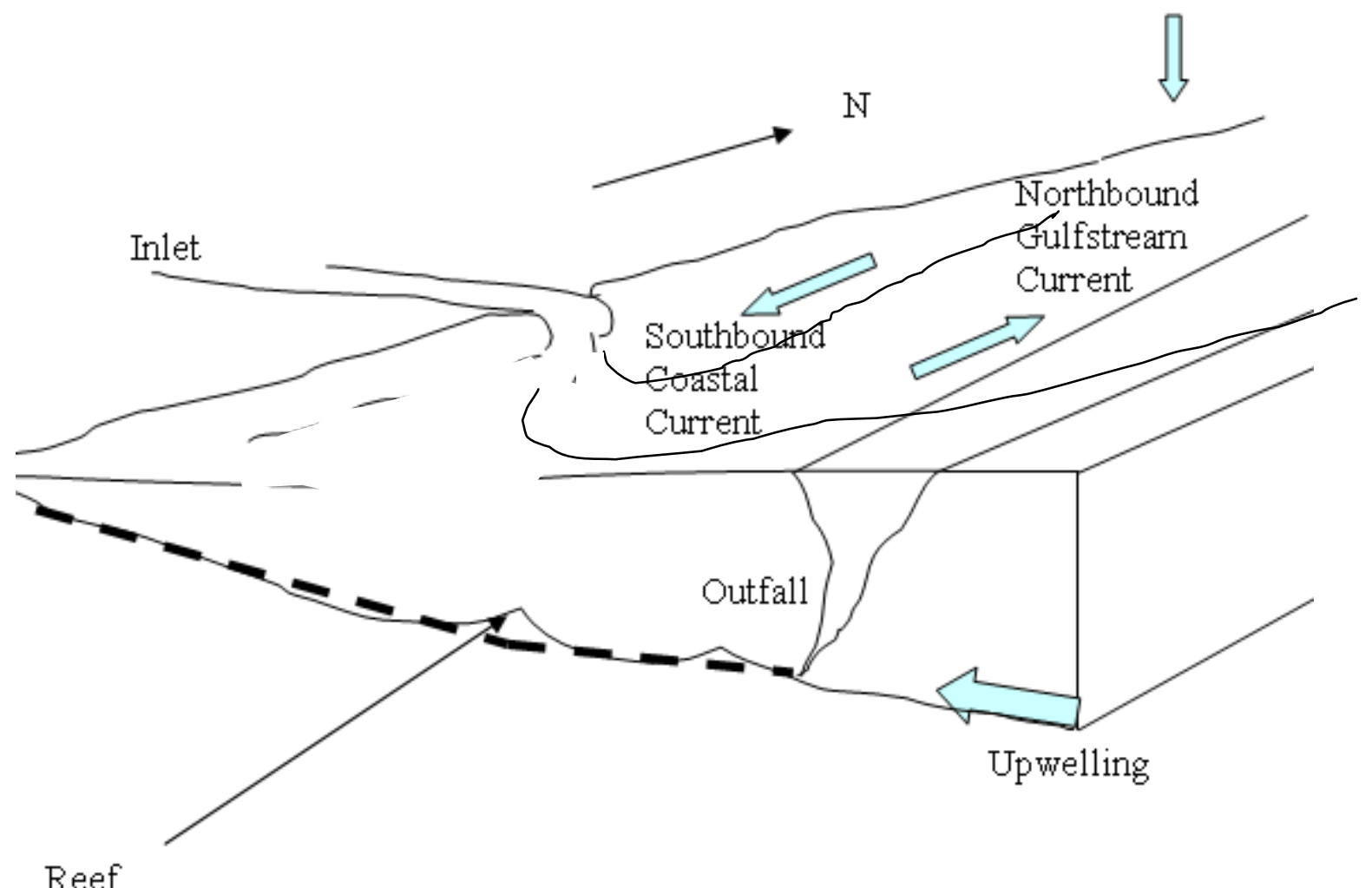

Impact?

Figure 5. Conceptual diagram of the Coastal ocean 
$\mathrm{x}$-axis

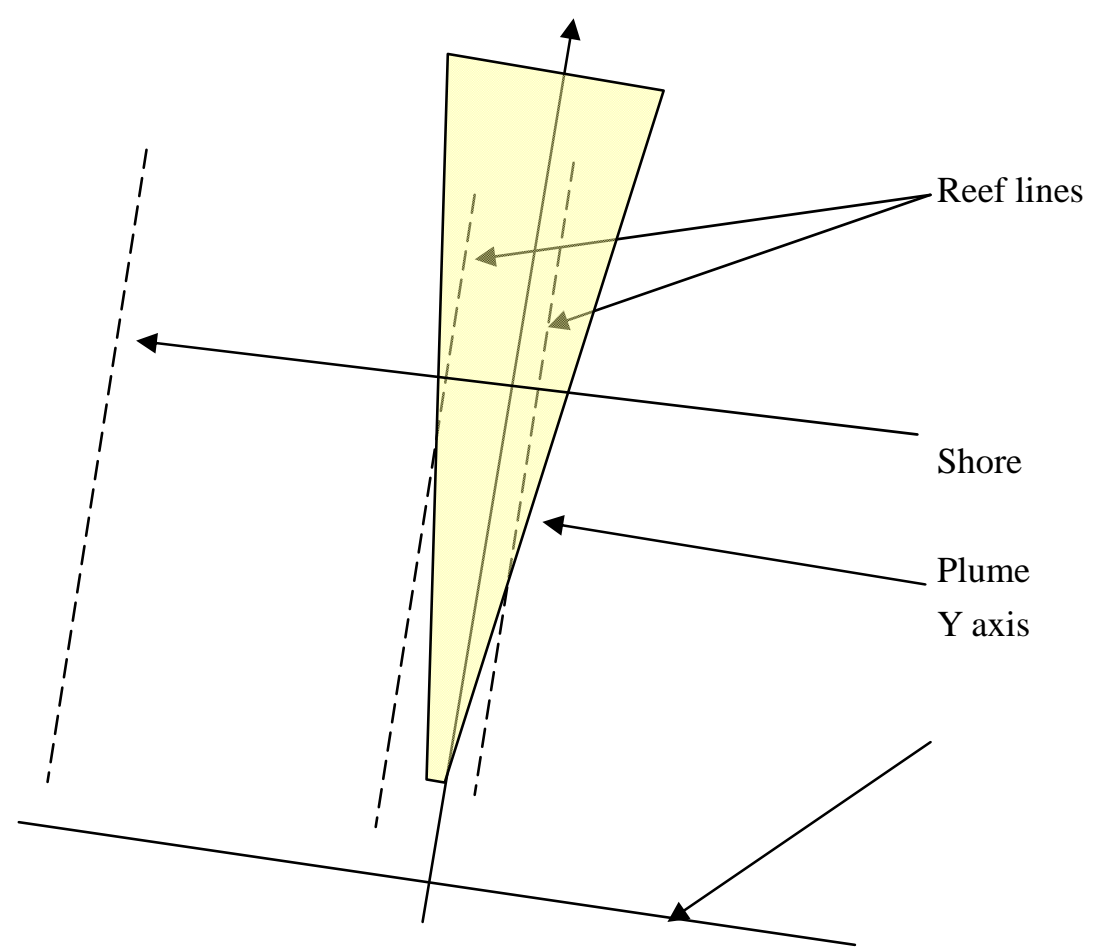

Figure 6. Top sketch of features in the model

The Gaussian plume model is a (relatively) simple mathematical model that is typically applied to point sources. One of the key assumptions of this model is that over short periods of time (such as a few hours) steady state conditions exist. Dispersion begins in three dimensions. The "standard" algorithm used in plume studies is the Gaussian plume model, developed in 1932 by O.G. Sutton. The equation is as follows:

$$
C(x, y, z, t)=\frac{Q}{2 \pi u \sigma_{y} \sigma_{z}} \exp \frac{-y^{2}}{\sigma_{y}{ }^{2}}\left(\exp \frac{-(z-h)^{2}}{2 \sigma_{z}{ }^{2}}+\exp \frac{-(z+h)^{2}}{2 \sigma_{z}{ }^{2}}\right)
$$

Where:

$\mathrm{Q}=$ mass of tracer

$\sigma_{\mathrm{y}}, \sigma_{\mathrm{z}}=$ dispersion coefficients

$\mathrm{u}=$ velocity

Equation 1 is an unbounded, three dimensional equation generally applied to air pollution. The same theory exists in water. All plume models have their basis as Gaussian models whereby the $\mathrm{x}$-axis is defined by an exponential distribution (where the velocity of the current drives the results - see Figure 5) and the y and $\mathrm{z}$ axes by a normal (Gaussian) distribution 
about the $\mathrm{x}$-axis. However, in this case, the $\mathrm{z}$ direction cannot continue to infinity as it is bounded on both sides so reflection is introduced. Okubo (1969) observed that a water column would be almost continually turbulent at a depth of 10-30 meters. Turbulence plus an outgoing plume with an average initial salinity of 36 ppm (Bloetscher and Meeroff, 2007), allow for the assumption that the low buoyancy plume is completely mixed over the water column soon after entering the coastal ocean. Aerial views after the dye was released confirmed the mixing. The assumption of complete mixing will result in a simplified version of the previous equation be deleting the $\mathrm{z}$-axis:

$$
c(y, z, t)=c_{p} \exp \left[-\frac{1}{2}\left(\frac{y^{2}}{\sigma_{y}^{2}}\right)\right]
$$

where $c_{p}$ is the best fit function describing the centerline concentration of the plume defined by:

$$
c_{p}=c(0,0, t)=\frac{Q}{\pi u_{0} \sigma_{y} \sigma_{z}}
$$

Like the z-axis, the y direction is limited on the west side of the centerline, but the distance from the shore to the centerline exceeds $0.4 \mathrm{~km}$, and the angle of the edge of the plume to the centerline is very slight angle, son an unbounded system was assumed in this case (note the southbound coastal current complicates modeling further and there is no existing data on the velocity of the southbound current in the vicinity of this inlet. For plumes in coastal water systems there are no general dispersion calculation parameters, and lateral diffusion calculation $\left(\sigma_{y}\right)$ has to rely on experimental data and/or theoretical derivations. As a result, the lateral dispersion results can be obtained from controlled tracer releases and the analysis of the patches formed as they diffuse (Lewis, 1997). For a Gaussian distribution the width $b$ between opposite points in a tracer patch which are $10 \%$ of the maximum concentration (the centerline) should be 4.3 times the standard deviation. For practical applications this number is generally rounded down to $4 \sigma$ (Lewis, 1997).

\section{Data Analysis and Results}

\subsection{Centerline}

The plume was detected moving north of the inlet with its cross-section in the latitude-water depth plane. The sampled points where binned with respect to their latitude to find the value and location of the highest concentration point at a given plume cross-section. The data ranged from latitudes $26.53916^{\circ}$ to $26.65934^{\circ}$ and was separated into uniform bins of $0.01^{\circ}$ (approximately $1.1 \mathrm{~km}$ ). Shorter bin widths than $0.01^{\circ}$ could not be used because most of the bins ended up containing half transects that did not include sample points of the $\mathrm{SF}_{6}$ tracer patch.

The centerline equation required a velocity. There were three ADCP devices to measure velocity (see Figure 6), although none were perfectly located as they describe the current on 


\section{Macrothink}

the reefs or between the coast and the reef barrier. From the historical data collected by NOAA, it was calculated that the mean current for the system goes north $89 \%$ of the time due to the influence of the Florida Current at $29 \mathrm{~cm} \mathrm{~s}^{-1}, 3$ meters below the surface, although southern currents are periodically registered (Proni, et al 2009). The difference between the coastal and the open ocean currents result in a shear zone that is especially important when the coastal waters flow south. ADCP data suggests that the line where the different ambient currents meet meanders east and west.

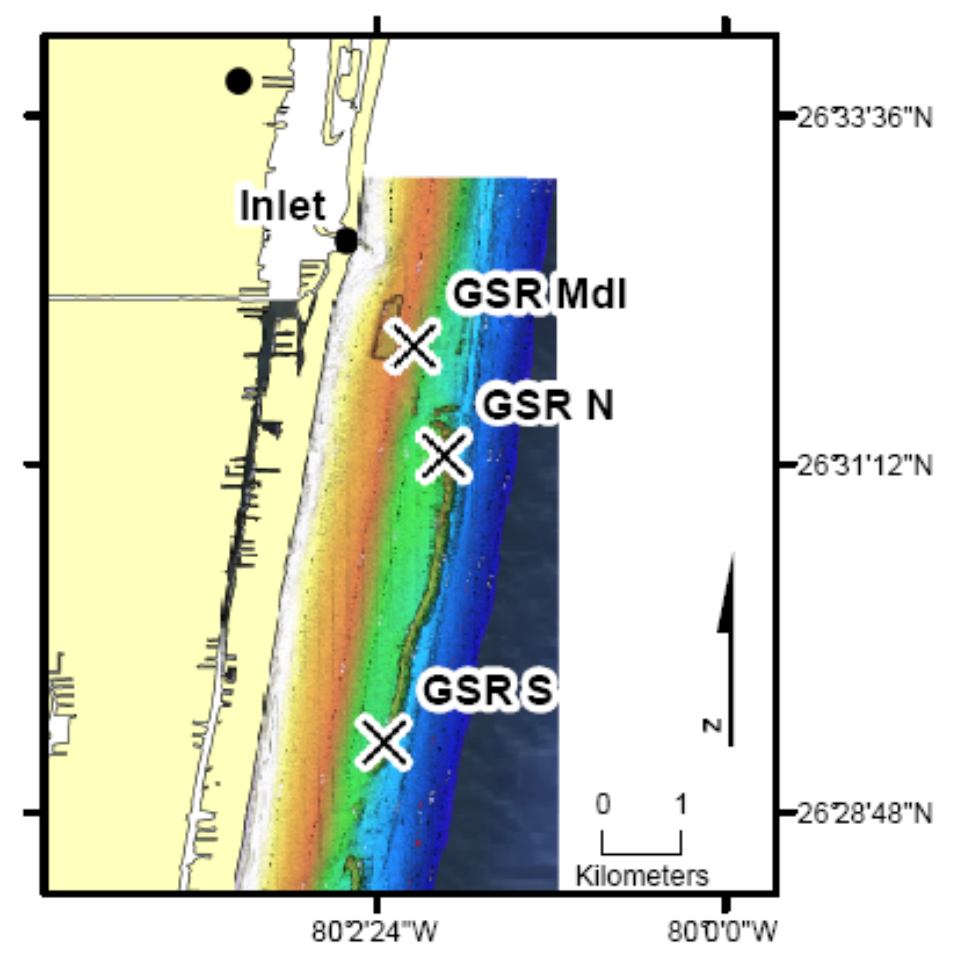

Figure 7. ADCPs locations, all south of the inlet (Pire-Schmidt, 2009)

During the experiment, using a plot of the concentration was plotted against time, indicated an average north velocity of $14 \mathrm{~cm} \mathrm{~s}^{-1}$. An exponential interpolation was used to find the trend function that best described the dilution of the $\mathrm{SF}_{6}$ with respect to time of travel. With the results derived the following exponential equation for change in concentration with time on the $\mathrm{x}$-axis:

$$
c_{p}(t)=125 \times \exp (-0.052 t)
$$

where $t$ is time, in hours and $c_{p}$ is concentration with respect to time, in pptr. It should be noted that as time approaches zero, the concentration of the centerline approaches 122 pptr, which was the highest, earliest, value recorded (see Figure 8). 


\section{Macrothink

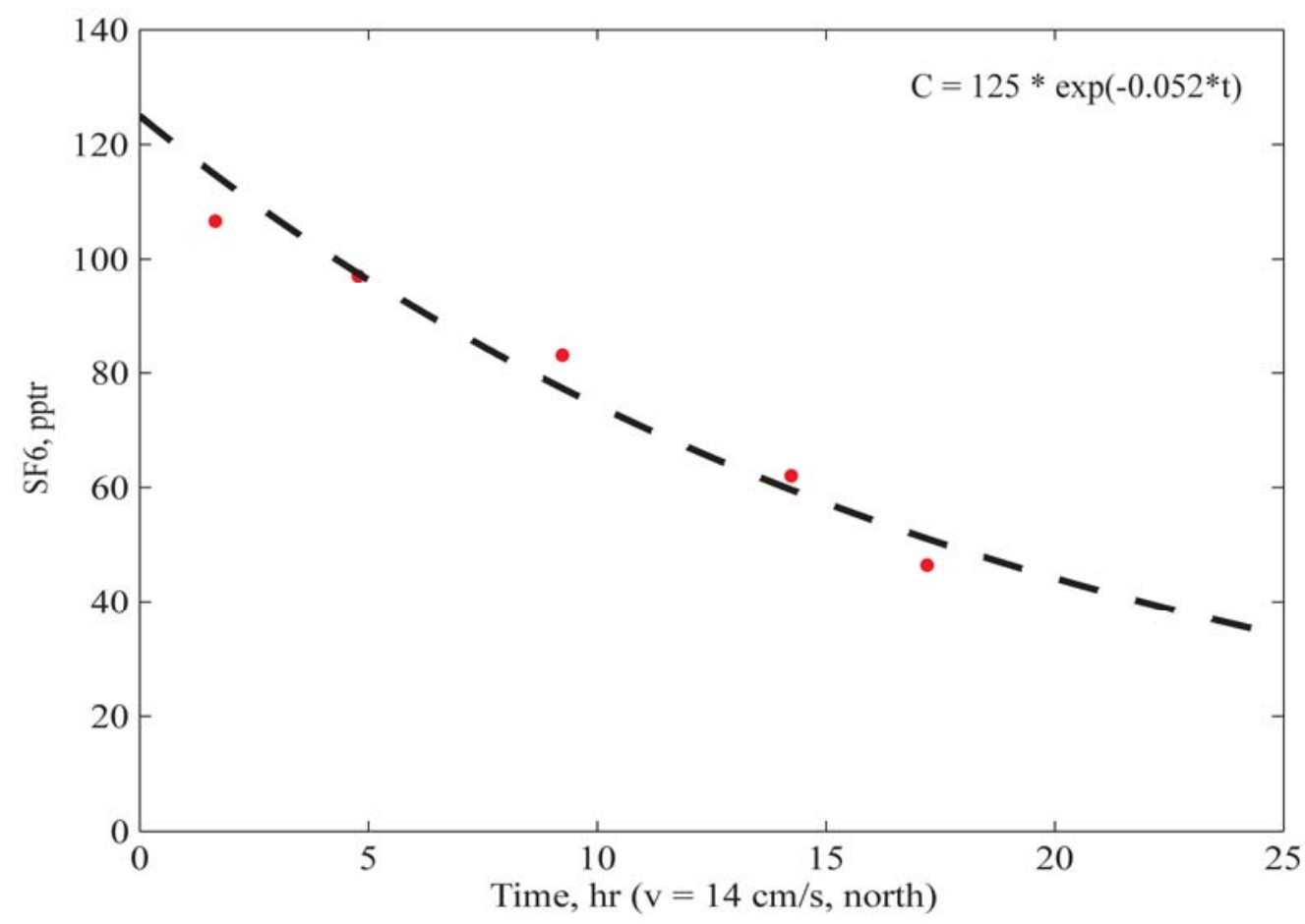

Figure 8. Centerline model. Graph for concentration vs. time (Pire-Schmidt, 2009)

\subsection{Horizontal Diffusion}

The experimental lateral dispersion for the $\mathrm{SF}_{6}$ plume was calculated using the sample values collected by the sampling boat as it went towards the centerline; direction east to west, each defined as a "Run." The closer to the plume, the more accurate the data is for creating the dispersion coefficients. The closest data resulted form Runs 1 and 2. Using the projected, interpolated, concentration maps, the lateral distance from the theoretical centerline to the $10 \%$ value of its concentration was estimated. This distance was assumed to be equal to two standard deviations form the mean ( $2 \sigma_{y}$, standard deviation for the lateral diffusion). This modeling is based on a grid were the $x$-axis is defined by the Earth's North-South axis (recall Figure 4), with $x$ values increasing northward and the $y$-axis represents the East-West axis, with values increasing eastward. The $(0,0)$ coordinate for the system is the inlet's mouth. From Run \#2 only the last two transects have positive values that would indicate the presence of the $\mathrm{SF}_{6}$ plume. This transects are referred as R\#2 North and R\#2 South (Figure 9). The standard deviation for the lateral diffusion $\left(\sigma_{y}\right)$ was calculated to be $850 \mathrm{~m}$ at the high concentration point of $106 \mathrm{pptr}, 900 \mathrm{~m}$ north of the inlet. Standard deviation of lateral diffusion for R\#2 North is $650 \mathrm{~m}$. 

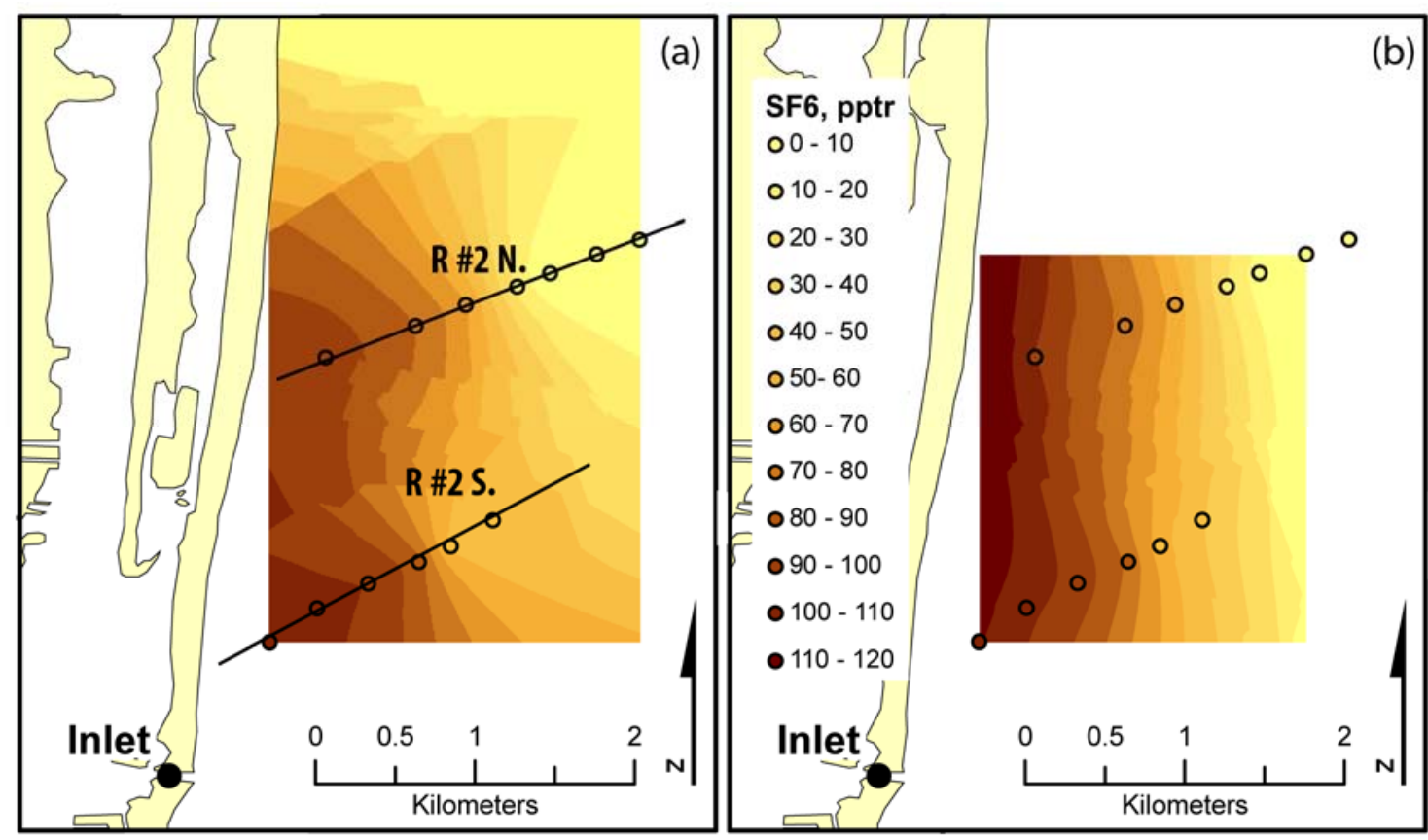

Figure 9. Run \#2, lateral diffusion. (a) Kriging for concentration, (b) Kriging, linear trend removed (Pire-Schmidt, 2009)

Figure 10 shows an idealized elongated patch to illustrate this hypothesis. This hypothesis is further supported by the fact that lateral diffusion for the north transect is lower than that for south one, which would indicate a contracting plume which would be impossible in a diffusive environment.

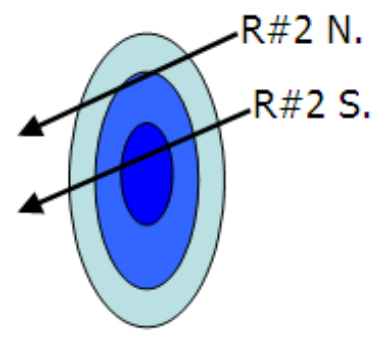

Figure 10. Idealized sketch of the sampling transects with respect to the tracer (tracer patch was not elliptical)

\section{MATLAB Model}

Using MATLAB ${ }^{\circledR}$, a model was created to calculate the plume from the initial time up to February 24. Based on observation, the centerline was assumed to be 400 meters off the coast, and concentrations west of the centerline were assumed to be equal to the centerline value. The following table summarizes the model: 
Table 1. MATLAB Model (Pire-Schmidt, 2009) 2012, Vol. 1, No. 2

\begin{tabular}{|r|l|}
\hline N-S model length & $35 \mathrm{~km}$ \\
\hline N-S grid size & $250 \mathrm{~m}$ \\
\hline E-W width & $4 \mathrm{~km}$ \\
\hline E-W grid size & $10 \mathrm{~m}$ \\
\hline CL distance & $400 \mathrm{~m}\left(400, y_{n}\right)$ \\
\hline
\end{tabular}

The equation solved by MATLAB was:

$$
c(0,0, t)=125 \times \exp (-0.052 t)\left[1+\exp \left(-\frac{1}{2}\left(\frac{y^{2}}{750^{2}}\right)\right)\right]
$$

The modeled plumes were projected into a map of the coastline for analysis (Figure 11).

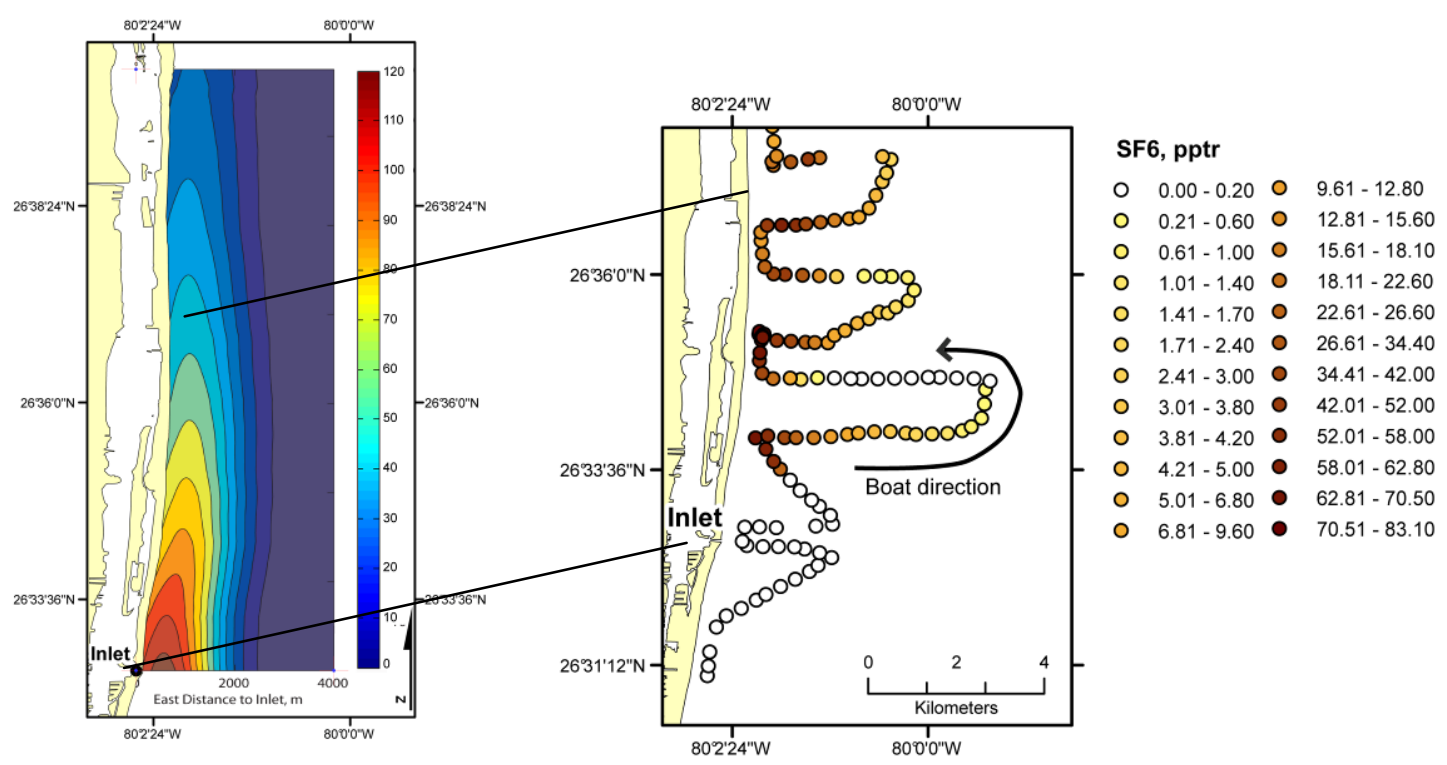

Figure 11. Plume model for February 24 (checkpoints in green) (Pire-Schmidt, 2009)

\subsection{Measuring the Efficacy of Model}

The error in the prediction of the $\mathrm{SF}_{6}$ concentration was low, with $75 \%$ of the errors being less than 2.45 pptr, and $90 \%$ of the samples with an error of less than 4.6 pptr. The value of the RMSE is higher than this, reflecting that although most of the errors are small, some 
extreme errors increased the average of the square of the residuals. Those errors were always overestimated. It should be noted, that the higher values belonging to the centerline were better predicted. The MAE indicates that the model overestimates the concentrations by an average of 1 pptr. The model underestimates most of the values with concentration above 9 pptr and overestimated values between 9 and 5 pptr, which may be due to velocity to changes in the coastal currents during tidal changes (see Figure 12).

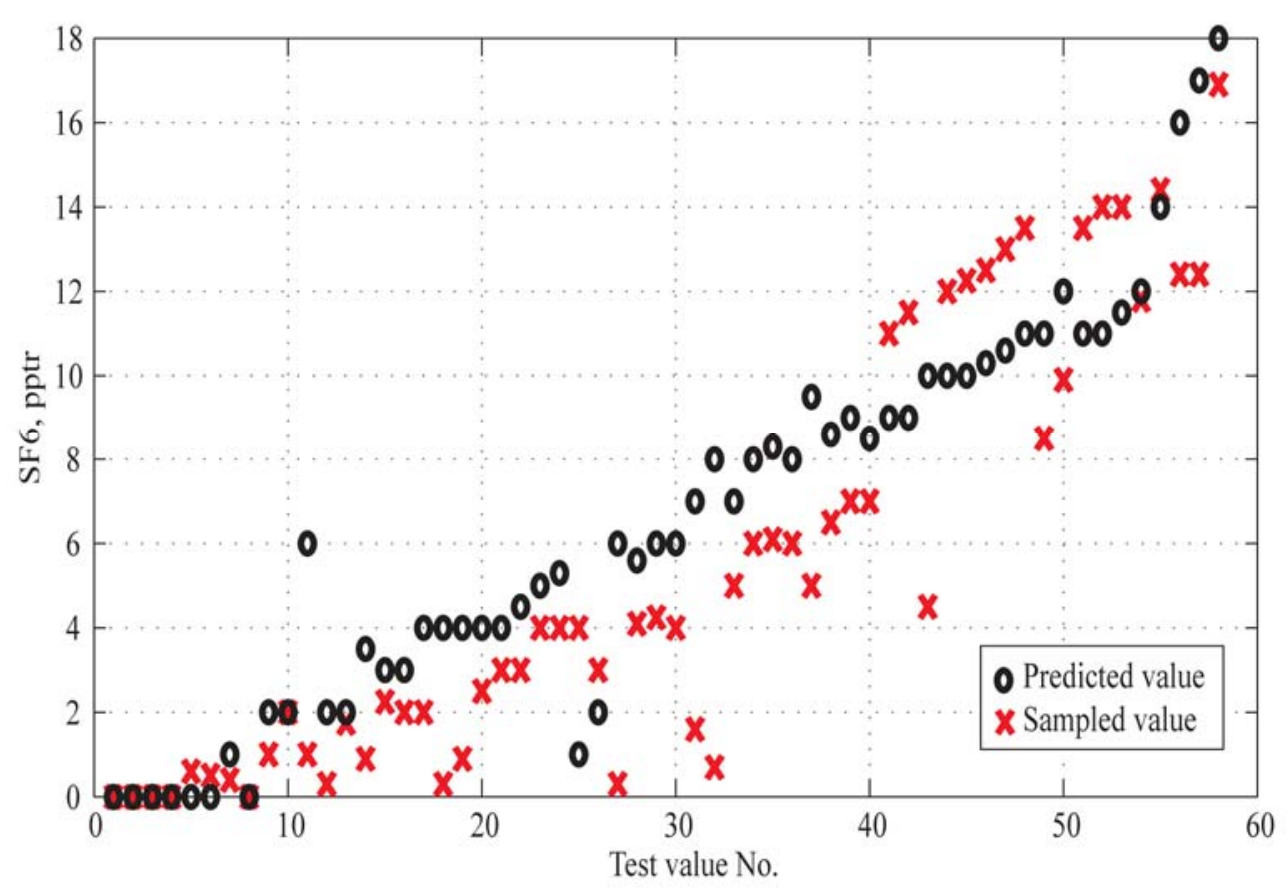

Figure 12. Predicted vs. actual values for February 24 (Pire-Schmidt, 2009)

To assess sensitivity of the model to changes in velocity and to calibrate the model, the contours were recalculated for ambient velocities that moved $+/-5 \mathrm{~cm} \mathrm{~s}^{-1}$ from the average velocity. Over a 24 hour period, this change in velocity would amount to $4.3 \mathrm{~km}$ in the distance covered. The results were far worse.

With respect to reef impact, Figure 13 shows the bathymetry compared toe model results. 


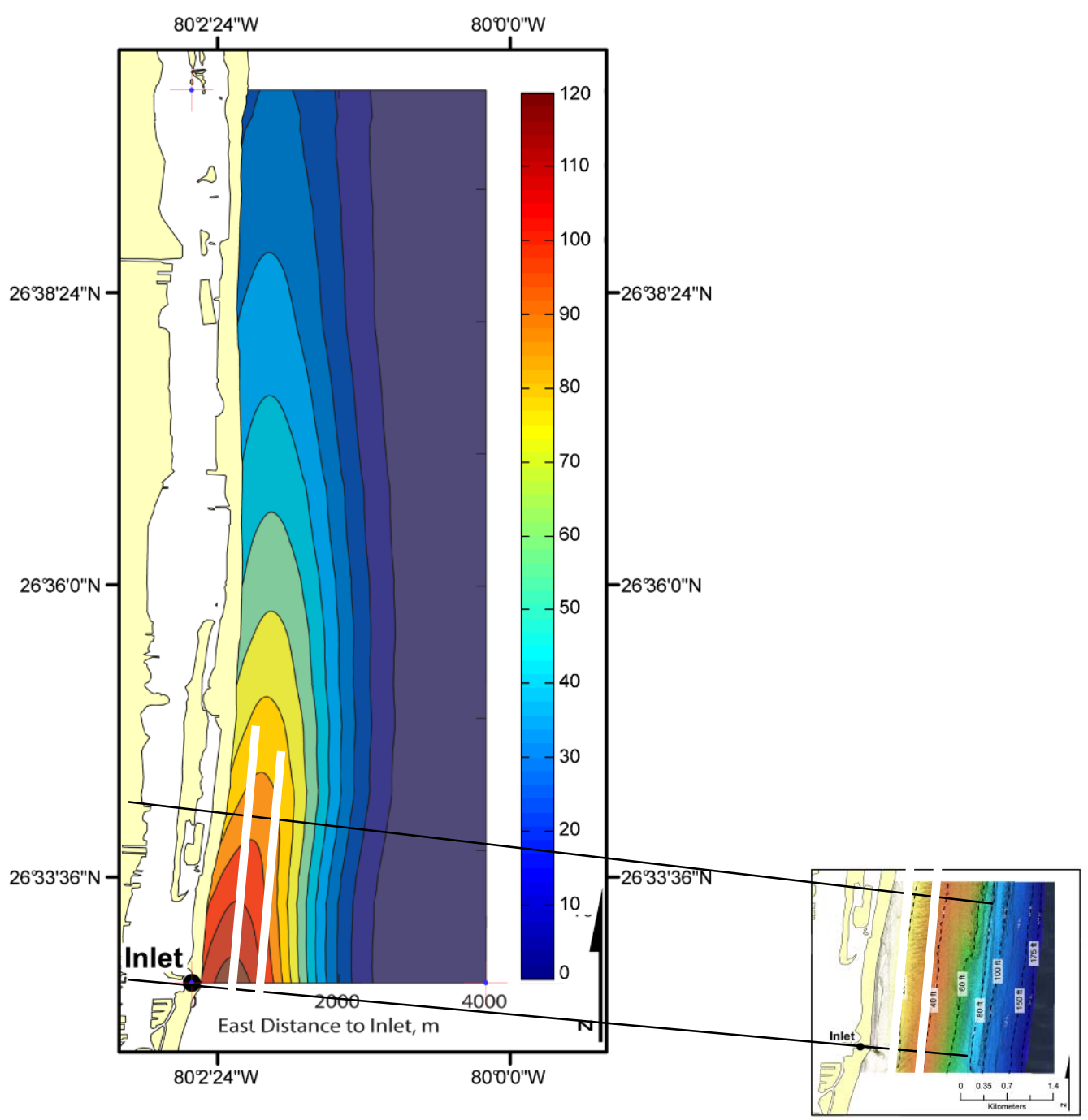

Figure 13. This figure shows the southern edge of the plume and the bathymetry of the inlet. The reef line is shown in white. This shows that the dilution of inlet concentrations affecting the 2 reef ridges varies from 3:1 to 6:1 in the vicinity of the inlet, and does not reach 10:1 until $10 \mathrm{~km}$ north of the inlet. Given results from Proni et al (2009) of $0.5 \mathrm{mg} / \mathrm{L}\left(\mathrm{NO}_{3}+\mathrm{NO}_{2}\right)$, $0.4 \mathrm{mg} / \mathrm{L}$ of ammonia and $0.12 \mathrm{mg} / \mathrm{L}$ of Phosphorous, the values are about 50 times higher than the typical background ocean concentrations, and greater than previously proposed ammonia limit of $0.035 \mathrm{mg} / \mathrm{L}$

The model results presented here indicate that modeling the farfield is possible. An important assumption for this project was that he tracer concentration was constant over the water column, suggesting that there was no significant buoyancy difference between the coastal water and the inlet water. Lab tests confirmed the viability of this assumption. The resulting model provided a good fit for the measured data and the impact of inlet discharges on the reefs. The fact that the tracer formed a patch instead of a plume suggests that the inlet plume was correctly modeled by using a Lagrangian approach. The results provide future investigators with a methodology to pursue future farfield projects inlet flow models and identifies some of the challenges to overcome. 


\section{Macrothink}

Tracking a tracer is an expensive project, which cannot be repeated numerous times. As a result, one limitation of the model is that it has data for only one discharge event. A general model, describing more than one discharge event would have to take into account that because current conditions change constantly at the inlet, the patches could have different trajectories. In addition, reefs and other offshore structures can obstruct water flow and create channels of water where the current intensity will be higher than ambient current. Hence the current meters may not properly measure the velocities unless precisely located. The current conditions at the reef barrier are not well understood or easily modeled and the calculation of the effect of individual reefs on the advection of the tracer is beyond the scope of this model.

The data sampled during this experiment shows that $\mathrm{SF}_{6}$ concentrations are higher on the coast. Moreover, the Florida Current appears to "hug" the side of the plume, providing a mechanism for entrainment of tracer into the coastal current. suggesting that all or at least most of the tracer is completely entrained in the coastal current. This comports with the findings of Okubo \& Karweit (1964).

\section{References}

Bloetscher, F. et al. (2007). Preproposal for Center of Excellence at Florida Atlantic University, Boca Raton, FL.

Bloetscher F., \& Meeroff, D.E. (Florida Atlantic University) (2007). Boynton Inlet sampling event; NOAA dye study coordination. Florida Atlantic University, Boca Raton: FL.

Creed, Christopher G. (2003), Modeling Inlet Sand Bypassing, Olsen Associates, Inc. Jacksonville, FL

Hodgens, E., \& Krecic, M (2008), South Lake Worth Inlet Surge Modeling Review, Taylor Engineering, Inc. Jacksonville, Florida.

Hoesman, Brian J. (2010), Behavior of Tidal Inlets During and After Severe Storms, A Thesis Submitted to the Graduate School of the University of Notre Dame in Partial Fulfillment of the Requirements for the Degree of Master of Science in Civil Engineering, South Bend, IN.

Huang, H., Fergen, R. E., Proni, J. R., \& Tsai, J. J. (1996). Probabilistic analysis of ocean outfall mixing zones. J. Environ. Eng. May $1996 . \quad 359-367$, http://dx.doi.org/10.1061/(ASCE)0733-9372(1996)122:5(359)

LaPointe, B. E., Barile, P. J., Littler, M. M., \& Littler, D. S. (2005). Macroalgal Blooms on Southeast Florida Coral Reefs II. Cross-shelf Discrimination of Nitrogen Sources Indicates Widespread Assimilation of Sewage Nitrogen. Harmful Algae, 4, 1106-1122, http://dx.doi.org/10.1016/j.hal.2005.06.002

Lewis, R. (1997). Dispersion in estuaries and coastal waters. West Sussex, England: John Wiley \& Sons Ltd. 


\section{Macrothink}

Environmental Management and Sustainable Development

ISSN 2164-7682

2012, Vol. 1, No. 2

Meeroff, D. E., Morin, F. J., \& Bloetscher, F. (2006). Proceedings from Florida Water Resource Conference (FWRC) 2006: Contribution Of On-Site Treatment And Disposal Systems On Coastal Pollutant Loading, FL: St. Cloud.

NOAA (National Oceanographic and Atmospheric Agency) (2009). Investigation of the South Central Regional Waste Water Treatment Plant and Coastal Environment. Florida Area Coast Environment

http://www.aoml.noaa.gov/themes/CoastalRegional/projects/FACE/SC-Final_2009.pdf

(FACE),

Okubo, A. (1969). Ocean mixing. Detroit: Management Information Services.

Okubo, A., \& Karweit, M. (1964). Diffusion from a continuous source in a uniform shear flow. Limnol. Oceanogr, 14, 514-520. http://www.aslo.org/lo/toc/vol_14/issue_4/0514.pdf

Pires-Schmidt, Joaquin. (2009). "Farfield Modeling of the Boynton Inlet Plume Using Sulfur Hexafluoride As Tracer“. MS Thesis Florida Atlantic University College of Engineering and Computer Science, Florida Atlantic University, Boca Raton, FL. http://www.grin.com/en/doc/282637/farfield-modeling-of-the-boynton-inlet-plume-using-sulf ur-hexafluoride

Proni, J., Adler, M., Amornthammarong, N., Bishop, J., Bloetscher, F., Carsey, T., ... Zhang, J. Z.. (2009). Final Report: An Investigation of the South Central Regional Wastewater Treatment Plant Ocean Outfall and Coastal Environment, http://www.aoml.noaa.gov/themes/CoastalRegional/projects/FACE/SC-Final_2009.pdf

Ramaswami, A., Milford, J. B., \& Small, M. J. (2005). Integrated environmental modeling. Pollutant transport, fate, and risk in the environment, John Wiley \& Sons, Hoboken, NJ.

Roberts, Philip. (1999). Modeling Mamala Bay Outfall Plumes. II: Far Field. J. Hydraul. Eng., 574-583, http://dx.doi.org/10.1061/(ASCE)0733-9429(1999)125:6(574)

Wanninkhof, R., Sullivan, K. F., Dammann, W. P., Proni, J. R., Bloetscher, F., Soloviev, A. V., \& Carsey, T. (2005). Farfield Tracing of a Point Source Discharge Plume in the Coastal Ocean Using Sulfur Hexafluoride. Environ. Sci. Technol., 39, No. 22, 8883-8890, http://www.aoml.noaa.gov/themes/CoastalRegional/projects/FACE/EST_2004.pdf

\section{Copyright Disclaimer}

Copyright reserved by the author(s).

This article is an open-access article distributed under the terms and conditions of the Creative Commons Attribution license (http://creativecommons.org/licenses/by/3.0/). 